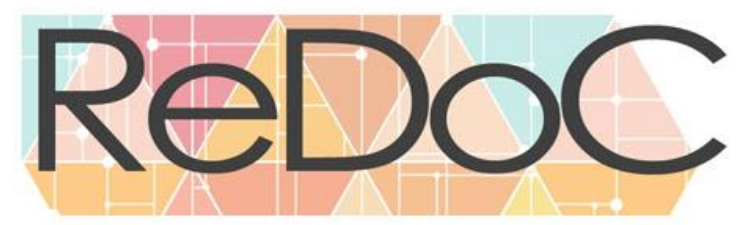

Revista Docência e Cibercultura

\title{
PROBLEMATIZANDO GÊNERO E SEXUALIDADE EM INTERLOCUÇÃO COM EDUCADORAS/RES DE UMA ESCOLA CONFESSIONAL-FILANTRÓPICA
}

\author{
PROBLEMATIZING GENDER AND SEXUALITY IN INTERLOCUTION WITH \\ TEACHERS FROM A CONFESSIONAL-PHILANTHROPIC SCHOOL
}

\author{
Fernando Altair Pocahy ${ }^{1}$ \\ Priscila Gomes Dornelles ${ }^{2}$
}

\section{RESUMO}

Este artigo analisa como determinadas redes discursivas se (re)produzem nos processos educativos diante dos dispositivos da sexualidade e das normas regulatórias de gênero, tomando como foco os discursos da heteronormatividade e sua potência na produção de subjetividades em cotidianos escolares. Para isso, dialogamos com os Estudos Feministas e queer de modo a privilegiar as produções no campo da Educação em interface com a escola. Como opção metodológica, este estudo analisou primariamente entrevistas realizadas em uma instituição confessional e filantrópica de ensino fundamental e médio, localizada em uma cidade de grande porte no estado do Ceará. Para tratamento deste material, utilizamos a análise de discurso inspirados/as em perspectiva foucaultiana. Esta abordagem teórico-analítica nos permitiu apontar que os/as educadores/ras assumem posições de sujeito localizadas em planos hetero/normativos, bem como disposições menos rígidas em relação a estes discursos. O que nos fez ponderar sobre

Submetido em: 05/04/2019

Aceito em: 20/04/2019

Publicado em: 01/06/2019

${ }^{1}$ Professor Adjunto da Universidade do Estado do Rio de Janeiro (UERJ) atuando na Faculdade de Educação, junto ao Departamento de Estudos Aplicados ao Ensino e ao Programa de Pós-Graduação em Educação (ProPEd). É coordenador do GENI - Grupo de Estudos em Gênero, Sexualidade e(m) Interseccionalidades na Educação e $(\mathrm{m})$ Saúde. Bolsista da FAPERJ no programa Jovem Cientista do Nosso Estado (2015-2018) e do Programa de Incentivo à Produção Científica, Técnica e Artística/ PROCIÊNCIA-UERJ-FAPERJ (início 2015, em vigência). É Doutor em Educação e Mestre em Psicologia Social e Institucional, ambos pela Universidade Federal do Rio Grande do Sul (UFRGS), com bolsa CAPES, vinculado respectivamente aos grupos GEERGE - Grupo de Estudos em Educação e Relações de Gênero e ao Laboratório de Psicologia e Políticas Públicas. É graduado em Psicologia pela Universidade do Vale do Rio dos Sinos (UNISINOS). Atualmente é Editor Associado da Revista Interface - Comunicação, Saúde e Educação - Unesp Botucatu.

${ }^{2}$ Licenciada em Educação Física pela UFRGS, é especialista em Pedagogias do Corpo e da Saúde, mestre e doutora em Educação ela mesma instituição. É integrante do Grupo de Estudos de Educação e Relações de Gênero (Geerge/UFRGS), do Gepefe/UFRB (Grupo de Estudos e Pesquisas e Educação, Formação de Professores e Educação Física) e do núcleo Capitu/ UFRB (Gênero, Diversidade e Sexualidade). Atualmente é professora do Centro de Formação de Professores da Universidade Federal do Recôncavo da Bahia (UFRB), professora vinculada ao Mestrado Profissional em Educação do Campo da UFRB e coordena o subprojeto de Educação Física do Pibid e o projeto de extensão "Futsal Feminino em Amargosa: rompendo fronteiras de gênero" na mesma instituição. Atua, prioritariamente, no âmbito das discussões/ações sobre formação de professores; Educação Física Escolar; relações de gênero, sexualidade, educação e educação do campo; estágio em Educação Física. 


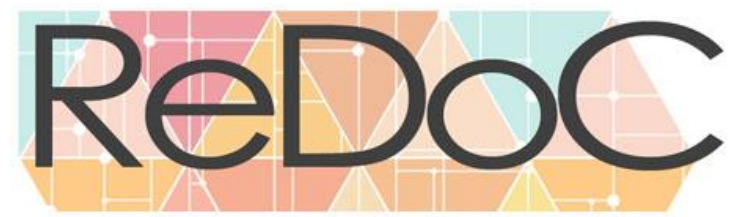

Revista Docência e Cibercultura

um arranjo difuso de conjuntos enunciativos materializados em pedagogias de gênero e da sexualidade nestes cotidianos escolares, ao mesmo tempo em que percebemos condutas pedagógicas que funcionavam de modo crítico em relação aos estabelecidos normativos. Estes resultados nos informam algo de uma agonística cotidiana na educação e, neste sentido, revelam movimentos que (re)posicionam professoras e professores diante das tramas da heteronormatividade - seja através das formas de sujeição e das ortopedias pedagógicas, seja no plano da resistência e (re)invenção de (micro)políticas do cotidiano escolar.

PALAVRAS-CHAVES: Educação; Escola; Gênero; Sexualidade; Heteronormatividade.

\begin{abstract}
This paper analyses how specific discursive webs are (re)produced in educational processes by the contrivances of sexuality and gender focusing the discourses of heteronormativity and its power in the production of subjectivities in school everyday. To do that, we dialogue with the queer and Feminist Studies to privilege productions in the field of Education in interface with school. As methodological option, this study firstly analysed interviews made in a confessional and philanthropic institution of elementary and secondary education, located in a crowded city in the state of Ceará/Brazil. To treat that material, we used the discourse analysis inspired on a foulcaultian perspective. That theoretical-analytical approach allowed us to point out that the educators assume a position as subjects located in hetero/homonormative plans as well as a little bit less strict dispositions related to those discourses. That made us ponder a diffuse arrangement of materialised enunciating sets in gender and sexuality pedagogies of that everyday school life as long as we also realise pedagogical conducts that worked out in a critical way in relation to the previously stablished as normative. Those results inform kind of an everyday agonistic in education and therefore reveal movements that (re)position teachers before the plots of heteronormativity as by forms of subjection and of pedagogical orthopaedics as on the resistance plan and (re)invention of (micro)policies of the school everyday.

Keywords: Education; School; Gender; Sexuality; Heteronormativity.
\end{abstract}

\title{
INTRODUÇÃO
}

A diversidade cultural e os dilemas de uma sociedade complexa e híbrida, como a nossa, fazem da escola o espectro plural, desigual e diverso da educação em nosso país. A institucionalização da educação básica no Brasil acontece, efetivamente, em desacordo com a pluralidade regional, institucional e desde as especificidades de seus diversos níveis de ensino e esferas de gestão - pública ou privada. Diante de tantas possibilidades culturais e contextuais, destacamos os efeitos dos compromissos biopolíticos (Foucault, 1997 [1976]) engendrados e 'assumidos' pela/na escola através da (re)produção de discursos sobre raça/etnia, gênero e sexualidade. Esta herança e fidelidade políticas se articulam enquanto dispositivos na ficção de um conceito de "humano ideal" assumido por discursos que busca(va)m hegemonia na educação. Vinculada a estes 'jogos' de poder característicos da modernidade, a escola ocupa certa evidência como um dos espaços sociais privilegiados nas tramas políticas geridas para a produção de modos

\begin{tabular}{l|l|} 
v. 3 & n.1
\end{tabular}

p. 128 Jan/Abr. 2019

e-ISSN 2594-9004 


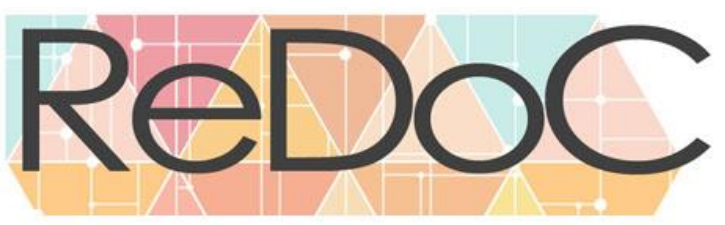

Revista Docência e Cibercultura

de vida e, mais amplamente, voltados à agonística social da democracia brasileira.

Nestes termos, consideramos as políticas públicas que definem e se articulam na composição do campo da educação (escolar) como práticas de subjetivação potentes na contemporaneidade. Nossa aposta consiste em assumirmos que a política pública, qualquer que seja ela, sempre e incondicionalmente, exerce uma pedagogia cultural ${ }^{3}$ ao propor e/ou informar algo na/da/sobre a produção de modos de vida. Isto é, uma política pública é, antes de tudo, uma produção político-discursiva através da qual os sujeitos estabelecem uma sorte de relações consigo mesmos diante de certos códigos morais e de determinados discursos estabelecidos, materializados em institucionalidades programáticas que cercam sua existência, a de seus pares e, mais amplamente, a de uma comunidade, um grupo ou um coletivo.

A esse movimento de produção do sujeito na contemporaneidade, inspirados/as em Foucault (1995), compreendemos os modos de subjetivação. Isto é, analisamos as políticas educativas em acordo com o argumento de que as subjetividades e as relações sociais se constituem em jogos de saber-poder oferecendo um ideal regulatório para as vidas, um ideal que oferece uma noção de humano que importa e, consequentemente, habilitado a circular nos domínios do viável e do possível na vida em sociedade e nos espaços educativos escolares como o sujeito escolar normal. Ao mesmo instante em que define uma ontologia política do que pensamos ser a cidadania, nestas tramas do poder produz-se uma marca indelével sobre o sentido do educar para sua época, lugar e cultura - estabelecendo os limites da participação social e da democracia como uma disputa constante.

Neste estudo, objetivaremos uma análise dos discursos em torno da sexualidade e das práticas regulatórias que definem o gênero na sua feitura binária (masculino e feminino). Dessa forma, ao engajarmo-nos em produções de estudiosas e estudiosos no campo da educação (Louro, 2011; Meyer, 2013) que visibilizam e/ou demarcam àqueles/as insurgentes e/ou contestantes das marcas do humano viável e possível neste jogo social, buscamos acompanhar movimentos que escapam à norma, o que inclui os processos heteronormativos que se deparam com "o silêncio, a

\footnotetext{
${ }^{3}$ Em diálogo com as proposições postas pelos Estudos Culturais, o conceito de pedagogia cultural é aqui apresentado como "qualquer instituição ou dispositivo cultural que, tal como a escola, esteja envolvido - em conexão com relações de poder - no processo de transmissão de atitudes e valores" (Silva, 2000, p.89).
} 


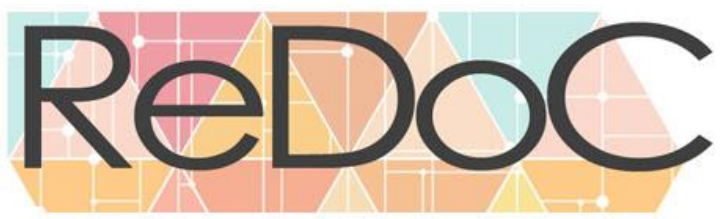

Revista Docência e Cibercultura

dissimulação ou a segregação" (Louro, 2000, p.27), assumindo que isso implica em evidenciar como esta estratégia política se constitui nos cotidianos escolares (Oliveira, 2001).

Estamos convencidos/as de que a escola constitui-se enquanto uma arena onde se (re)produzem hierarquias, desigualdades, injustiças e sofrimento de forma contundente quando, especificamente, atrelados às dimensões gênero-sexuais da constituição do sujeito escolar. Autoras/es como Guacira Lopes Louro, Dagmar Meyer e Fernando Seffner, em algumas de suas obras tratadas ao longo deste artigo, destacam a dimensão de saber-poder onde currículo e cotidiano se oferecem como espaços de reificação de normas e exclusões. Ao mesmo tempo, a escola e a educação básica se colocam como lugar possível de reinvenção dos novos modos de fazer política e desde onde emergem novas subjetividades, articuladas ao jogo da produção de conhecimento no cotidiano.

Entendemos o currículo e o cotidiano escolar para além de estreitezas conceituas sobre os processos formais de ensino-aprendizagem e os conteúdos selecionados. Tratamos destas dimensões como um arranjo por onde determinada sociedade produz os sentidos institucionalizados pelo Estado como (im)próprios para a vida (em sociedade). Ou seja, nos referimos às epistemologias ${ }^{4}$ do mundo produzidas nos territórios educacionais. Buscamos, assim, compreender como a educação opera, conforma e constitui elementos para pensar-viver a sexualidade e as relações de gênero - como dimensões importantes na constituição dos sujeitos escolares, conforme já apostamos em outra ocasião (Pocahy e Dornelles, 2011).

A diáspora dos sujeitos objetivados nos discursos da heteronormatividade ocupa muitas das cenas cotidianas da educação e da escola. Esta norma que atua na "produção e [...] reiteração compulsória da norma heterossexual"(Louro, 2009, p. 90) se imbrica aos (e se retroalimenta dos) processos de ensino-aprendizagem como um regime político arbitrário que opera no sentido de determinar práticas e condutas normativas gendradas (no sentido atribuído por De Lauretis (2006 [1994])), ao afirmar as marcas de gênero como elementos de produção do que nos cerca). A heteronorma atua, também, regulando as experimentações da sexualidade ao pressupor a

\footnotetext{
${ }^{4}$ Referimo-nos a regimes de verdade que autorizam alguns/algumas a organizar e narrar as experiências políticas e socioculturais do conhecimento no espaço escolar. Acrescentamos a isso as apostas de Britzman (1996) quando afirma que todo conhecimento contém suas próprias ignorâncias, no sentido em que seleciona, privilegia e localiza objetos e sujeitos no jogo do conhecimento.
} 


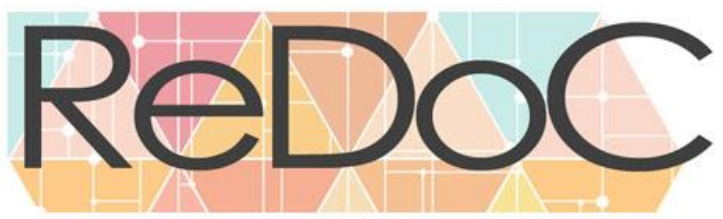

Revista Docência e Cibercultura

heterossexualidade como obrigatória (Rich, 1981), ou seja, ficcionada em suposta evidência, naturalidade e incontestabilidade.

Porém, é no cotidiano escolar onde são reveladas também sobrevivências-resistências de costumes, tradições e normas. Oliveira (2001, p.43) nos agita a pensar as práticas cotidianas, "procurando nelas, não as marcas da estrutura social que as iguala e padroniza, mas sobretudo, os traços de uma lógica de produção de ações de sujeitos reais, atores e autores de suas vidas irredutível à lógica estrutural, porque plural e diferenciada”. Os/As sujeitos escolares (professores/as, discentes, gestão escolar, por exemplo) podem agir como modificadores/modificadoras das relações de saber-poder que eles/elas estão supostamente submetidos/as.

No rastro destas ideias, alojamo-nos em um tipo de problematização que toma como princípio a ética a partir de Foucault (2001a/ 1984), especificamente, quando este conceito aponta relações com a ampliação das margens de liberdade de determinadas relações sociais/processos de subjetivação. Este processo também se constitui em sua dimensão estética, uma vez que agencia a possibilidade de certa (re)invenção de si e contorno singular (como uma sorte de efeito do jogo da produção da diferença) para a subjetividade. Tudo isso produzido na agonística da política - o plano privilegiado da subjetivação, isto é, o plano de disputa, de oposições, de confronto, de ruptura e de acontecimentos, insurgências e insubordinações micropolíticas.

No entanto, cabe sublinhar, as interpelações que (re)definem as possibilidades de organização de determinado espaço de prática educativa se oferecem como enunciados na produção e exercício de pedagogias que estabelecem hierarquias e posições de aprendizagem e a consolidação de epistemologias sobre o mundo, manchadas pelos discursos etno-sexo-gendrados e entre outras intersecções destes marcadores e posições articuladas às políticas de conhecimento. No caso de uma articulação com o campo da educação escolar, recorremos às proposições de Seffner (2011) quando afirma que:

A escola, vale repetir, é espaço público, objeto de políticas públicas, e nela o convívio respeitoso da diversidade deve acontecer. A mesma consideração aqui feita para questões de gênero e sexualidade vale para diferenças de raça, cor, origem regional, classe social, pertencimento religioso, ordenamento familiar, etc. Todos devem ser respeitados, e 
cumprir o que dizem o regimento escolar e o projeto político pedagógico da escola, que não pode estabelecer discriminações." (2011, p.9).

As provocações indicadas por Seffner (2011) sobre os compromissos da educação escolar em articulação com as dimensões teóricas que tratamos ao longo desta seção assentam e conduzem a nossa investigação sobre a produção de relações socioculturais na perspectiva de gênero e sexualidade, a partir de uma cartografia dos esquemas pedagógicos, curriculares e institucionais que este território educacional nos permitiu problematizar.

\section{MÉTODO}

Esta pesquisa possui design qualitativo, a partir da aplicação de um protocolo único (roteiro de entrevista semi-estruturada) dividido em a) aspectos sociodemográficos, incluindo-se os elementos relacionados à formação docente; e $b$ ) questionamentos acerca de temas e situações de cotidiano escolar relacionados a gênero e sexualidade. Os/as interlocutores/ras foram convidados/as a participar da pesquisa através de apresentação da equipe de pesquisa em reuniões na escola com a companhia de coordenadores e coordenadoras pedagógicos do estabelecimento de ensino e o trabalho com as entrevistas realizou-se durante o mês de novembro de 2012.

$\mathrm{Na}$ composição dos dados congregamos algumas posições destes/destas educadores entre planos/ posições normativas, fronteiriças e críticas. Diante deste arranjo (um tanto arbitrário, mas operativo) pudemos observar elementos de uma agonística social que cerca a experiência educacional, não como um elemento exterior (o fora da escola, a sociedade 'entrando' na escola), mas como um regime político-discursivo que define o interior de suas próprias práticas e das condições próprias deste grupo estabelecendo micropolíticas de um cotidiano educacional.

Optamos por não analisar separadamente os núcleos/ planos. Decidimos destacar elementos de oposição, tensão e encontros naquilo que nos pareceu mais próximo do cotidiano: por onde e por quais caminhos no conjunto dos dados as normas se atualizam, reatualizam, marcando os modos de produzir e habitar a escola. 


\section{INTERLOCUTORES/RAS DA PESQUISA}

O estabelecimento de ensino que acolheu a pesquisa opera no ensino fundamental e médio. Trata-se de instituição filantrópica e religiosa (católica). A escola atende a aproximadamente 2.000 estudantes da cidade e arredores, alguns e algumas desses/as discentes depositários de pequenas quantias na manutenção da matrícula. Apenas uma pequena parcela matriculada está isenta de qualquer pagamento, contemplados/as com bolsa integral. A escola oferece cursos profissionalizantes nas áreas tecnológica e de serviços, como cursos de garçom e manutenção de computadores, por exemplo. As atividades religiosas fazem parte do cotidiano da comunidade escolar, onde a presença de padres e algumas missionárias reforçam o projeto confessional: "Educar e promover as crianças em situação de risco ensinando-lhes o gosto pelo trabalho" (informação obtida no site da instituição).

Nosso trabalho se apoia nas contribuições de 19 professoras/res do total de 40 profissionais envolvidos/as nos dois níveis de ensino ofertados pela escola (fundamental II e médio). O número de adesões corresponde a disponibilidade dos educadores e das educadoras no período do trabalho de campo, efetivamente também associado à disponibilidade pessoal diante da proposta - o que permitiu que abrangêssemos $50 \%$ do corpo docente.

Acessamos 6 interlocutores/as da Área de Ciências Exatas e Biológicas, atuando 3 deles na disciplina de Biologia, 2 na disciplina de Química e 1 na disciplina de Matemática; possuem Média de renda: R\$1.975,2 (Menor renda: R\$776,00 - Maior renda: R\$4.000,00); Média de idade: 42 anos (Mais jovem: 29 anos - Mais velho: 54 anos); Religião: 83,3\% católicos e 16,6\% Testemunho de Jeová; Formação: 66,6\% apenas graduação, 33,3\% Especialização como maior titulação; Tempo médio de atuação como professor/a: 9,3 anos (Menor tempo de experiência: 3 anos - Maior tempo de experiência: 15 anos); Posição do grupo em relação à temática da pesquisa: 66,6\% normativas $-33,3 \%$ fronteiriços $-0 \%$ críticos. 


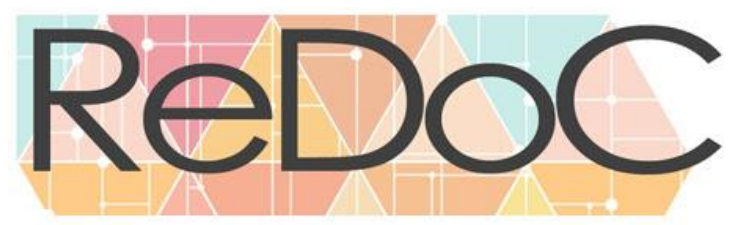

Revista Docência e Cibercultura

O total de educadores/ras da área de Ciências Humanas corresponde a 13 interlocutores/as, com média da idade: 39 anos (Menor idade: 24 anos - Maior idade: 54 anos); Religião: 92,3\% católicos - 7,6\% não se encaixa em alguma religião; Formação: 69.2\% graduados/as e 30,7\% com especialização como maior titulação; Tempo médio de atuação como professor: 11 anos (Menor tempo de experiência: 1 ano - Maior tempo de experiência: 24 anos); Grupo de classificação: $53,8 \%$ crítica $-30,7 \%$ normativa $-15,3 \%$ sedimentada; Disciplinas: 46,1\% história (dentro dessa porcentagem, 33,3\% também ministram filosofia) $-7,6 \%$ inglês $-23 \%$ português $-7,6 \%$ geografia - 15,3\% Educação Física.

Aos/às professores/ras que se dispuseram colaborar ofertamos um cronograma de horários inserido no expediente docente e organizado pela coordenação pedagógica geral da escola. A produção de dados foi realizada durante o período de uma semana letiva no mês de novembro de 2012, através de inserções da equipe composta de 5 mestrandas em Psicologia e 5 alunas/os de Iniciação Científica, vinculadas ao laboratório de estudos coordenado pelo primeiro autor do artigo, à época vinculado à Universidade de Fortaleza.

\section{PRESSUPOSTOS E PROCEDIMENTOS ÉTICOS DA PESQUISA}

A dimensão ética da investigação que originou este artigo está associada ao conceito de “cosmopolitismo crítico" apontado por Rabinow (1999), onde o principio condutor da pesquisa é em si e por si uma questão de ética - no plano de alargamento das possibilidades de liberdade das/dos interlocutoras/res na pesquisa, sejam estas pessoas ou instituições. Para este autor,

O princípio condutor é ético. Esta é uma posição oposicionista, desconfiada de poderes soberanos, verdades universais, precisão relativizada em demasia, autenticidade local, moralismo de cima e de baixo. Entendimento é o seu outro valor, mas um entendimento desconfiado de suas tendências imperialistas. Esta posição presta atenção às - e respeita diferenças, mas também está alerta à tendência de essencializá-las. (p.100) 


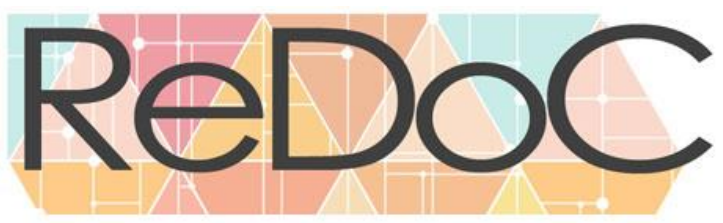

Em consonância aos pressupostos de Rabinow (supracitado) tratamos de formular a construção das entradas de análise para a pesquisa a partir de um "movimento de (re)composição de cenas do cotidiano, reunindo as contradições, contestações, as continuidades e as descontinuidades que marcam as representações em torno do corpo e de suas performances de gênero, no exercício da sexualidade a partir de uma postura ético-reflexiva. Modo este de recusa ao olhar excitado e objetificante - que muitas vezes é encontrado em pesquisas sobre as ditas práticas e vidas 'abjetas"”, como nos aporta Pocahy (2011; p.32).

Além desta dimensão ética, o projeto foi submetido ao Comitê de Ética, através de registro na Plataforma Brasil como forma de avaliação dos procedimentos da pesquisa. O projeto foi devidamente aprovado sob o número 03162012.2.0000.505.

Ao considerarmos que nosso trabalho se dirige em interlocução com pessoas tomamos especial atenção à resolução 466/12 do Comitê de Ética em Pesquisa do Ministério da Saúde que orienta a pesquisa "envolvendo seres humanos", reafirmamos que o princípio ético que conduz esta pesquisa encontra-se associado às provocações de Edward MacRae (2006) em atender aos preceitos do rigor e do cuidado em pesquisa, mas salientando que os temas que emergem de nossa proposta se relacionam a aspectos de demasiada preocupação institucional, controle e especialíssima atenção moral. Por esse motivo, todos os trâmites institucionais foram realizados, mas sem deixar de considerar que o tema de sexualidade, muitas vezes, encontra seus primeiros desafios de entendimento no campo das distintas moralidades que cercam o fazer cotidiano, produzindo repercussões no instante em que é acionado como tema de pesquisa.

O projeto foi apresentado à diretoria pedagógica e geral e às coordenações pedagógicas da escola. Nesta ocasião, obtivemos a anuência e a parceria da instituição para o desenvolvimento da pesquisa e todas/os as/os interlocutoras/es assinaram os Termos de Consentimento Livre e Esclarecido. Incorporou-se às nossas preocupações éticas a devolução do estudo, ocasião para o maior adensamento das problematizações através de novos espaços de interlocução. No entanto, em decorrência de uma mudança na direção do estabelecimento, não houve adesão da nova gestão à parceria; esse fato nos impossibilitou de avançarmos em uma proposta de 'tensionamento' dos dados junto a esta comunidade escolar. 


\section{FERRAMENTAS CONCEITUAIS DE ANÁLISE}

O corpus desta investigação foi produzido e composto pelas respostas individuais a um conjunto de questionamentos que foram produzidos na revisão de estudos e pesquisas que vêm se ocupando do trabalho de formação docente e práticas de cotidiano escolar na sua relação com a heteronormatividade (Dornelles \& Meyer, 2013; Dornelles \& Givigi, 2013; Quartiero \& Nardi, 2012; Bento, 2011; Pocahy \& Dornelles, 2011; Junqueira, 2009; Borges \& Meyer, 2008). Para isso, elaboramos três núcleos enunciativos que nos permitiram perceber os discursos que coabitam um cotidiano escolar e que se (des)articulam, produzindo as posições que os sujeitos educadores/ras ocupam nesta trama agonística investigada.

Os questionamentos dirigidos a esta comunidade escolar privilegiaram pontos de interesse que, mesmo que não estejam sistematizados na análise geral aqui descrita, ofereceram condições das composições dos conjuntos de enunciados estabelecidos a partir de nossos questionamentos:

a) Perguntamos às educadoras e aos educadores sobre os atributos mais importantes e esperados para mulheres e homens em nossa sociedade e se a escola tem influenciado sobre a formulação, produção e/ou manutenção destes atributos, solicitando-lhes exemplos do cotidiano.

b) Sobre a formação profissional questionamos se em algum momento foram orientadas/orientados a lidar com questões relacionadas à diversidade cultural, religiosa, étnicoracial, sobre as deficiências, sobre gênero e/ou sexualidade e como isso ocorreu, em caso positivo. Perguntamos ainda se elas e eles já participaram de alguma formação sobre a temática da sexualidade e educação.

d) No rastro desta questão, investigamos se já presenciaram alguma situação de cotidiano escolar relacionada à discriminação motivada pela orientação sexual e qual foi o encaminhamento institucional. Perguntamos aos/às interlocutores/ras sobre quais seriam os fatores mais significativos para a produção de atitudes discriminatórias na sociedade brasileira e se a escola contribuiria e como contribuiria para a produção da discriminação por orientação por raça/etnia, deficiências, por orientação sexual e por gênero?

e) Examinamos ainda se o grupo docente tinha conhecimento de alguma iniciativa sobre o enfrentamento à homofobia ou da discriminação por orientação sexual na educação escolar e o que 


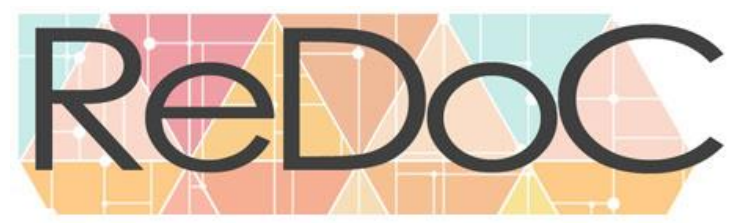

Revista Docência e Cibercultura

pensava sobre tal iniciativa. Interessamo-nos também em saber se eles/elas participariam de alguma formação específica relacionada a estes temas e quais seriam os aspectos de abordagem mais importantes para este tipo de formação, bem como quais estariam aptos a ministrar este tipo de formação.

O tratamento das informações do campo privilegiou a composição de nucleações enunciativas a partir dos agrupamentos e reagrupamentos construídos a partir de uma primeira análise e organização das informações construídas na interlocução com o grupo de 19 educadores/as. Deste modo, o Núcleo 1 consiste em entrevistas em aproximação com discursos que nos permitem refletir sobre os regimes de verdade hétero/normativos sedimentados (normativos); o Núcleo 2 - entrevistas em discursos que apontam para movimentos híbridos entre posições normativas e críticas (fronteiriças); e o Núcleo 3 - entrevistas que indicam efeitos de discursos críticos e relativamente contestatórios às hétero/normas. Esta nucleação não encerra a possibilidade de trânsito entre as posições ocupadas pelos/as professores/as em suas falas, mas oferecem um plano possível de organização e identificação dos arranjos de significação das práticas pedagógicas cotidianas na escola investigada.

\section{RESULTADOS E DISCUSSÃO}

A escola e suas pedagogias como políticas de subjetivação instauram normas, bem como possibilidades de resistência. Conjuga-se, aí, um contraditório improvável na agonística da democracia e nas disputas sobre a noção de humano/ sujeito escolar: potência de vida e mortificação do desejo em um mesmo espaço - a escola.

Especificamente sobre as entrevistas críticas, indicamos o reconhecimento de posições mais flexíveis com relação às questões de gênero. Contudo, ainda assim, as análises indicaram rastros dos discursos heteronormativos e hétero/sexistas nas falas deste grupo. Em geral, os/as interlocutores/as qualificados/as como críticos/as apresentam uma visão complexa das produções normativas, mas o limite das posições encontra seu maior desafio nos ecos institucionais, uma vez 


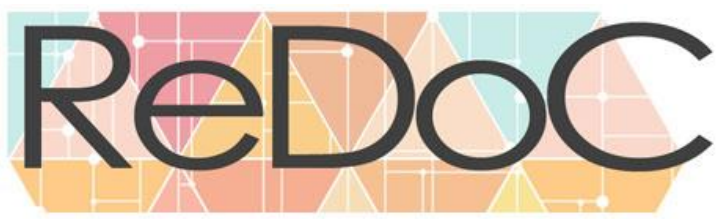

Revista Docência e Cibercultura

que o estabelecimento porta uma marca religiosa de grande expressão, sendo reconhecido no contexto da cidade pela tradição e compromissos com as pedagogias cristãs.

Observamos na contribuição da interlocutora Beatriz, 24 anos, professora de Literatura e Artes que: "[a sociedade] diz que não espera [coisas diferentes do homem e da mulher]. Ela sempre vai esperar coisas diferentes porque a nossa sociedade atual por mais que se diga muito, minha opinião, querendo igualdade, sempre vai querer diferenciar de alguma forma.”. O que nos permite adensar a discussão de que ao gênero são atribuídas significações que dizem respeito à forma de se comportar, a partir da materialidade 'irredutível' dos corpos. Os homens são vistos como fortes, provedores e racionais, enquanto as mulheres são sensíveis e submissas, além de serem responsáveis pelo cuidar e proteger, performance essa que pode ser atribuída à maternidade. Neste aspecto, o que se constituiria enquanto uma diferença 'naturalizada', opera de forma a manter as hierarquias de gênero, seu essencialismo binário e as desigualdades decorrentes destas marcas de poder-saber. Segundo Meyer (2003a) essas noções são apresentadas como se fizessem parte da natureza das mulheres que se tornam, por exemplo, mães, norteando muitos dos processos educativos através dos quais alguém se torna homem ou mulher, pai ou mãe.

Percebemos a circulação comum de discursos relativos à divisão de gênero no trabalho na qual o argumento principal é a desigualdade construída socialmente entre homens e mulheres no âmbito do produto dos regimes de produção - como as especialidades no campo do trabalho, bem como no retorno salarial diferenciado. Apesar de algumas mudanças contemporâneas dos lugares e posições ocupadas pelas mulheres na sociedade brasileira, os/as interlocutores/as apontam que ainda existe uma grande submissão aos homens e/ou ainda persiste a visão da mulher como cuidadora, como uma condição social de reconhecimento. Deste modo, a noção de mulher "naturalmente" responsável por diversas instâncias de cuidado e vinculada a uma maternidade compulsória são expressões de uma feminilidade contemporânea que, simultaneamente, não nega o desejo e a atuação nos espaços de públicos e de trabalho. No entanto, podemos observar tensões e desencaixes nessas representações, a partir dos seguintes argumentos:

A sociedade não espera mais isso do homem ou da mulher, a sociedade quer uma coisa só: capital. Pelo menos a sociedade capitalista" (Pedro, 41 anos, professor de História). 
Tem uma questão que eu coloquei muito, a gente tá trabalhando isso tanto com os alunos do Fundamental quanto do Ensino Médio, é como a gente faz a correlação entre a Terceira Revolução Industrial e o tempo histórico e dentro disso um tema que foi muito abordado foi justamente a sexualidade, a questão do gênero, a questão da mulher como força de trabalho, do homem como rever seus conceitos, a sociedade mudando seu comportamento e os dois crescendo juntos nessa capacidade de interação maior na questão do gênero. $\mathrm{Ou}$ seja, a sociedade caminhando para você desassociar ou desconstruir o conceito do machismo. E a gente tem isso ainda muito forte. (Lucas, 46 anos, professor de História)

Nas entrevistas que apresentam ecos críticos percebe-se algo das repercussões dos deslocamentos presentes nas propostas feministas. Nestas posições, observa-se o reconhecimento do avanço das lutas das mulheres na sociedade brasileira, contudo, ainda reconhece-se a presença masculina como opressora e a quem estas precisam, em geral, se colocar em situação de submissão. Dessa forma, se por uma parte percebe-se tensionamentos nas representações sociais de feminilidade e masculinidade, por outra há discursos de gênero essencialistas que atravessam a fala dos/das entrevistados/as. Na análise do material empírico, estes discursos operam sustentando a sensibilidade e a emoção como atributos femininos, bem como indicam a força e o trabalho como características intrinsicamente masculinas. Este argumento pode ser observado nas ponderações de Osvaldo, 54 anos, professor de Química: “A gente sempre espera delicadeza. Que usasse mais o emocional do que o racional, a sensibilidade. As mulheres são muito mais espertas que os homens, vejo pela minha mãe, tem uma percepção muito melhor de que os homens, elas veem coisas que os homens não veem. (...) Os homens são mais racionais, machistas. Eu fui criado assim, né? Os pais da gente... Mas quando a gente quer quebrar isso fica difícil...” Já Patrícia, 49 anos, professora de História ressalta:

A mulher tá tomando mais espaço, e se a gente tá tomado mais espaço é porque eles estão deixando. Claro que não necessariamente pra um ganhar o outro tem que perder, mas se abre espaço é porque a mulher tá estudando mais, ela tá indo em busca, ela tá indo a luta. Certo? Talvez até pra dizer pra sociedade que ela também é capaz, não só a figura do homem, do macho.

Os/as interlocutores/as em perspectivas mais fronteiriças referem dificuldades sobre questionamentos relativos a gênero e ao exercício da sexualidade, como elementos que correspondem à dimensão cultural e política destas experiências. No entanto, são profícuas as 


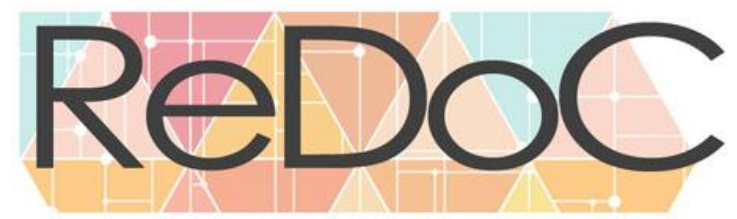

Revista Docência e Cibercultura

noções que remetem a essas, como podemos perceber nos argumentos de Mariana, 54 anos, professora de Português, Literatura e Artes:

\begin{abstract}
Atualmente a sociedade mudou os valores, os valores da concepção que Deus nos ensinou. Agora está tudo tão moderno, tão diferente, embora eu não aceite porque eu vou pela palavra de Deus, mas as famílias mudaram a formação, é mulher com mulher, homem com homem e a gente deve, aceitar não, mas pelo menos tentar conviver com esse tipo de pessoas porque aceitar tá longe pra quem tem um princípio religioso, mas não podemos discriminar.
\end{abstract}

O sexismo (expresso de forma contundente no machismo) é bastante presente no contexto sociocultural nordestino e cearense, como no Brasil de forma em geral. Seus efeitos podem ser percebidos nas falas dos/das entrevistados/as de maneira sutil e, por vezes, esfumaçada: "Eu acho que a mulher tem que refletir bastante sobre essa questão que quer um ambiente de trabalho, quer ser mulher e quer ser mãe e eu acho que isso através de um debate é possível, mas desde que não haja queima de etapas". As mulheres entrevistadas dizem perceber o machismo, como os efeitos pessoais e sociais dele expressos em sentença tais como: “homem é pra mandar e mulher é pra cozinhar", como afirma Mariana, interlocutora supracitada.

Nas entrevistas críticas percebemos a recorrência da menção da escola como espaço social que reflete a organização social e conjectura suas produções. Por isso, estes/estas entrevistados/as indicam a força desta instituição na manutenção das representações de gênero e de sexualidade “dominantes" apresentadas ao longo deste artigo. Para eles/elas, "A escola é mantedora do sistema. Assim como as religiões, a política, os meios de comunicação, as universidades"(Pedro, 41 anos, professor de História). De forma geral, estes/as interlocutores/ras reconhecem que a interferência das instituições sobre o indivíduo, seu corpo e sua sexualidade, produzindo marcas, condutas políticas, sociais e institucionais consideradas normais e/ou corretas.

Contudo, a norma pode funcionar em desalinho com os ideais de igualdade entre os sujeitos sociais. Os argumentos de Sabrina, 35 anos, professora de História, Filosofia, Sociologia e Formação Humana nos permite compreender esta ideia de um lugar de tensões entre normas e formas de contestação: “a escola reflete a sociedade, então ela precisa mudar partindo mesmo dos professores que estão mais próximos dos alunos, mesmo que a estrutura não permita, cabe a nós 


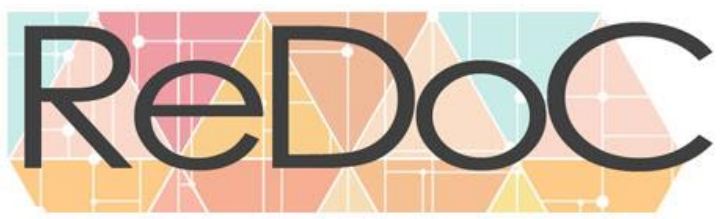

Revista Docência e Cibercultura

mostrar pra eles que é uma igualdade, que precisa tratar melhor por ser homem ou mulher. Então eu acho que a escola tem que trabalhar mais essa questão da igualdade.”.

Neste sentido, Dagmar Meyer (2003b) quando aponta que "os indivíduos aprendem desde muito cedo - eu diria que hoje desde o útero - a ocupar e/ou a reconhecer seus lugares sociais e aprendem isso em diferentes instâncias do social, através de estratégias sutis, refinadas e naturalizadas" (p. 22) nos ajuda a analisar as contribuições da instituição escolar na produção generificada dos sujeitos sociais. A pesquisadora apresenta o termo "pedagogias culturais" para expor a ideia de como algumas instâncias agem cotidianamente na definição dos modos de ser humanamente possível nas tramas do gênero. Para ela "[o conceito de pedagogias culturais amplia] as noções de educação e de educativo, e com ele pretende englobar forças e processos que incluem família e a escolarização, mas que estão muito longe de se limitar a elas ou, ainda, de se harmonizar com elas" (2003b, p. 22). Nestes termos, ponderamos que a escola opera na produção dos sujeitos de gênero para além dos espaços de trabalho considerados curriculares (no sentido estrito do termo). Ou seja, quando a escola indica e aciona práticas voltadas para os processos de ensino e aprendizagem.

Os diversos tempos-espaços escolares, os modos de ocupação do pátio, de distribuição dos/das discentes, de acesso e de exclusão de determinadas funções, espaços e situações escolares produzem (e são produzidos por) discursos de gênero. Deste modo, a instituição escola, em sua complexidade, participa da produção de gênero (e também de sexualidade), porém não é a única responsável em virtude de trabalharmos com uma perspectiva que considera as diferentes pedagogias culturais como definidoras dos sujeitos. Ainda sobre a potência da escola nesta produção generificada, Louro considera que:

As instituições escolares constituíram-se nas sociedades urbanas, em instâncias privilegiadas de formação das identidades de gênero e sexuais, com padrões claramente estabelecidos, regulamentados e legislação capazes de separar, ordenar e normalizar cada um/uma e todos/as. (2000, p. 47).

Os/as interlocutores/as que compõem o quadro de argumentos ditos mais normativos acrescentam o lugar da família na produção e manutenção dos discursos acerca do binarismo de gênero. Para eles/elas, alunos e alunas trazem "esses pensamentos e condutas" de casa. Dornelles 


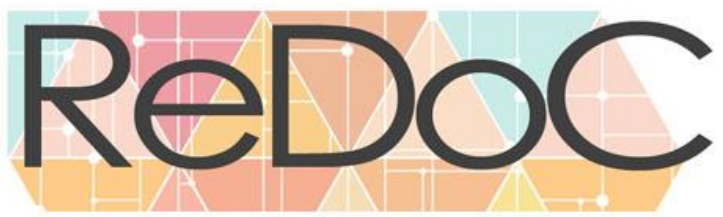

Revista Docência e Cibercultura

(2013), ao investigar como a Educação Física escolar (hetero)normaliza os sujeitos escolares através de suas práticas pedagógicas, analisou como as falas de docentes indicam a família como responsável pela educação de gênero. Porém, esta autora contrapõe este argumento visibilizando os modos (não reconhecidos) cotidianos que a disciplina de Educação Física promove ensinamentos heteronormativos quanto à vivência do gênero e da sexualidade na escola. $\mathrm{O}$ argumento de Joana, 29 anos, professora de Ciências do Ensino Fundamental II e Biologia do Ensino Médio, nos auxilia nesta conjectura:

A escola tem grande influência, grande influência mesmo com relação principalmente na formação do indivíduo. Nós sabemos que o professor faz toda a diferença. Porém eu não acho que essa responsabilidade deveria ser só do professor, só da escola, só da instituição. Tem que ser principalmente uma grande responsabilidade dos pais porque eles que vão realmente formar cidadãos para a sociedade. Nós complementamos, mas é um complemento significativo.

Esses argumentos nos permitem ainda encontrar elementos na compreensão da produção sociocultural da LGBTQI+fobia, assumindo no gênero uma de suas formas de sustentação e suspeita sobre a sexualidade. Isto é, o fantasma da (homo)sexualidade ou das sexualidades dissidentes à heterossexualidade compulsória é revestido pelo lençol normativo do binarismo de gênero e da heteronormatividade. Louro (2010) ao referir-se à homofobia na escola utiliza a noção de apartheid sexual e assinala: "consentida e ensinada na escola, a homofobia se expressa pelo afastamento, pela imposição do ridículo. Como se a homossexualidade fosse "contagiosa", cria-se uma grande resistência em demonstrar simpatia para com os sujeitos homossexuais: a aproximação pode ser interpretada como uma adesão a tal prática ou identidade”. (p. 29).

No argumento da professora Mariana (Língua Portuguesa, Literatura e Artes) encontramos movimentos que exemplificam essa ancoragem binária, elemento basilar para a produção de uma cultura homofóbica e heteronormativa:

A gente sempre espera delicadeza. Que usasse mais o emocional do que o racional, a sensibilidade. As mulheres são muito mais espertas que os homens, vejo pela minha mãe, tem uma percepção muito melhor de que os homens, elas veem coisas que os homens não veem. Então, essa percepção, essa sensibilidade, essa capacidade de agir com a emoção... Os homens são mais racionais, machistas. Eu fui criado assim, né? Os pais da gente... Mas quando a gente quer quebrar isso fica difícil. 


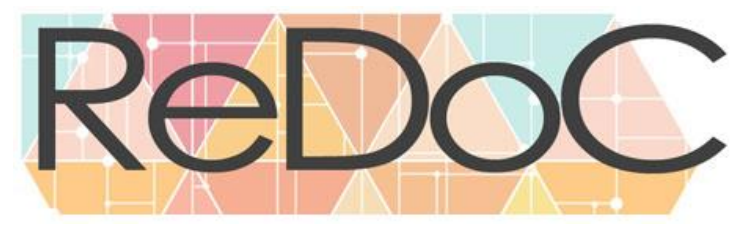

Revista Docência e Cibercultura

O excerto acima indica que, na escola, há uma grande necessidade de uma diferenciação dos gêneros, a qual é operada pela assunção do sexo como distinção binária fundante do sujeito. Priorizam-se, assim, as características biológicas como referencia primordial para essa distinção.

Louro (2012) considera que a homofobia é uma das formas de "manter" a (hétero) norma e 'naturalidade das coisas' e refere que a linguagem é um importante meio para isso: "Dentre os múltiplos espaços e as muitas instâncias onde se pode observar a instituição das distinções e das desigualdades, a linguagem é, seguramente, o campo mais eficaz e persistente - tanto porque ela atravessa e constitui a maioria de nossas práticas, como porque ela nos parece, quase sempre muito "natural"”. (p. 69).

Boa parte dos/as professores/as que apresentam perspectivas mais críticas possuem uma definição aproximada e congruente em relação a esta definição de "homofobia" (apenas um entrevistado não apresentou um argumento consistente sobre o conceito), porém se sentiram inseguros/as quando solicitados/as para conceituar o termo. Lucas, 46 anos, professor de História, por exemplo, declara que a homofobia: "É a aversão e de certa forma violenta ao comportamento homoafetivo ou homossexual. Uso da violência pra proibir essas coisas".

Algumas interlocutoras e alguns interlocutores relataram que casos de homofobia ocorrem rotineiramente, sendo a violência verbal a mais comum. A injúria surge assim como ato de humilhação e de demarcação de um sujeito possível na escola, mas também o sujeito a ser corrigido. O encaminhamento dado na instituição quase sempre gira em torno de levar o caso à coordenação e de conversas "moralistas"(sic.) sobre igualdade, visando de maneira sutil uma adequação dos sujeitos desviantes da norma a um padrão usual exigido pela sociedade.

Citando os argumentos do professor Lucas: "A gente presencia isso praticamente no dia a dia, né? Quando tem alguma discussão é sempre “Ah, porque você é 'viado', ah, porque você é "sapatão" e a gente tenta, dentro da função do educador, orientar pra melhorar principalmente o linguajar e o respeito pelo outro. Porque se não houver respeito pelo outro nas suas escolhas, a gente não consegue nosso objetivo.”. Já Katarina, 33 anos, responsável pela disciplina de Geografia, sustenta: “O encaminhamento, foram chamados os dois alunos pela coordenação para 


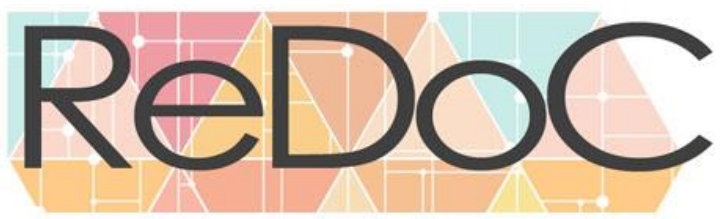

Revista Docência e Cibercultura

tentar resolver da melhor maneira possível em relação a opção sexual de um determinado... De um desses alunos."

As educadoras e os educadores reconhecem como fatores que favorecem o preconceito os efeitos da mídia e da família. Elas e eles percebem a escola como mantenedora de diversos tipos de discriminação (sexual, gênero, raça-etnia e deficiência), seja pela precariedade ou ausência na formação e preparo dos educadores/ das educadoras, segundo elas e eles, e ainda pelas condições práticas-materiais-instrumentais para lidar com essas questões ou por falta de acessibilidade (no caso de pessoas com algum tipo de limitação física).

Nas entrevistas qualificadas como normativas e fronteiriças nota-se que os professores não possuem uma noção segura sobre o termo "homofobia" e alguns ligam o sufixo da palavra ("fobia") a um medo qualquer e outros pensam que apenas casos de agressão física são classificados como homofobia, descartando a violência verbal e psicológica. A partir da confusão ao conceituar o termo, eles acabam negligenciando os casos concretos de violência na escola, alegando não ter presenciado nenhum tipo de preconceito. Percebemos nas falas das professoras algo desta trama que opera na ausência de referencias linguísticas e cotidianas sobre as formas de discriminação expressa na heteronormatividade. Andrezza, 54 anos, professora do Ensino Fundamental: Ciências e Ensino Médio: Biologia afirma "Homofobia? Já sei: É medo de... Homofobia... eu já ouvi falar...pois é... não sei se é medo... questão sexual, ou se é medo de... fobia é medo, né? Homossexual? Pois é, com relação a homossexualismo."

De outra parte, estes dilemas da indiferença e do não reconhecimento da violência homofóbica se expressam pela invisibilidade, como podemos depreender dos argumentos de Joana, 29 anos, Ciências do Ensino Fundamental II e Biologia do Ensino Médio: "Eu nunca estive numa situação que eu presenciasse na íntegra, em todos os termos uma pessoa se referir a outra por conta dela ser homossexual e ter tamanha violência ou agressão verbal."

Os/as interlocutores/as creditam à produção de discriminação os valores culturais. Muitos relatos referem os aspectos religiosos ocupando importância nestas situações. Não acreditam que a escola contribui na produção de discriminações, afirmam que lá o objetivo maior é a igualdade e que o mais próximo de discriminação seria por deficiência, pelo fato da escola não possuir a 


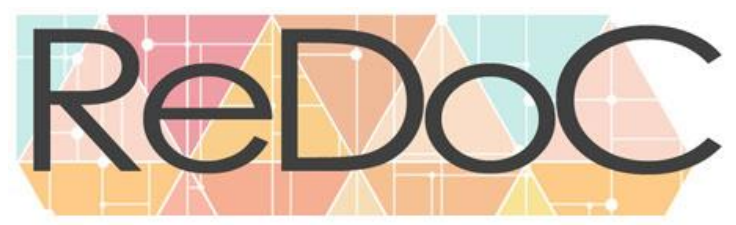

\section{Revista Docência e Cibercultura}

acessibilidade necessária. Novamente Joana, 29 anos, nos oferece alguns argumentos que explicitam o deslocamento de uma crítica normativa para o campo da moral religiosa:

As pessoas é que não fazem questão de parar pra ler um livro como a bíblia que é um livro tão precioso e de tanta profundeza. [...]Então, se todos nós temos acesso a esse conteúdo, por que não nos aprofundarmos? Porque ninguém que seguiu o que tá lá dentro da bíblia não se deu mal, ao contrário, só de dá bem porque é orientação divina, entende? Então o que eu penso, é que a questão de hoje é a falta de amor, amor ao próximo, valores morais.

É recorrente nas entrevistas críticas o fato de que a escola reflete a sociedade. E conjectura também suas produções, por isso ela acabaria influenciando na manutenção destas representações de gênero e sexualidade. Percebemos em algumas interlocuções a interferência das instituições sobre o indivíduo, em seu corpo e na sua sexualidade, produzindo marcas, condutas politicamente, socialmente e religiosamente corretas: "A escola é mantedora do sistema. Assim como as religiões, a política, os meios de comunicação, as universidades", afirma Pedro, 41 anos, professor de História. De forma geral, estes/as interlocutores/ras reconhecem que mesmo mantendo-se essas produções, a escola deve promover ideais de igualdade. Esta perspectiva mais 'flexível' pode ser mais bem compreendida nos argumentos de Natividade (2009):

A revisão dos estudos disponíveis sugere que, ao menos em um plano normativo, há religiões em que haveria espaço para uma relativa valorização da diversidade sexual (como as afro-brasileiras), enquanto posicionamentos católicos e evangélicos expressariam a persistência de uma rejeição às praticas homossexuais, qualificadas como pecado a partir de diferentes estratégias discursivas. Estas tendências hegemônicas não eliminam a existência de vozes e iniciativas dissidentes no interior das igrejas cristãs, conduzidas por lideranças que flexibilizam as prescrições normativas da igreja(...) (p. 128)

Em relação ao preparo dos/das educadores/ras diante destes desafios que os/as interpelam no cotidiano escolar, Junqueira (2009) afirma que os/as "profissionais da educação, no entanto, ainda não contam com suficientes diretrizes e instrumentos adequados para enfrentar os desafios relacionados aos direitos sexuais e à diversidade sexual" (p. 34). Esta constatação é compreendida por nós através do conjunto de argumentos coletados de que entre este grupo não haveria quem 


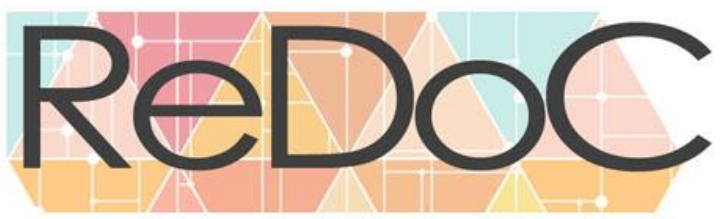

Revista Docência e Cibercultura

possuísse conhecimento sobre estratégias de enfrentamento à discriminação na educação escolar, seja nas instituições que trabalham ou não.

Porém, relatam que há um discurso moralista sobre igualdade em sala de aula visando uma melhor convivência entre os discentes fazendo com que estes "aceitem" e "respeitem" a diversidade. Os/as educadores/as acreditam que seria de grande importância a criação de novas estratégias de enfrentamento e lamentam a não existência destas. Pedro, 41 anos, professor de História, se interroga: "Na escola? Não. Assim, as coordenadoras entram em sala, leem textos mas não voltadas à orientação, mas sobre respeito, as liberdades. Mas, não... “Ah, vamos falar sobre sexualidade”. Que eu saiba, não.”. Já para Joana, 29 anos, Ciências do Ensino Fundamental II e Biologia do Ensino Médio: "Na realidade, nós aqui da Escola somos incentivados a trabalhar muito sobre a questão de valores e nesses valores entram muito essas questões aí, a questão do preconceito, do palavrão, insultos, a questão do bullying. Então sempre há atitudes dos professores sobre isso."

A grande maioria dos/as interlocutores/as afirma que participariam de alguma formação que envolvesse as temáticas discutidas, e como abordagens a serem discutidas nesta destacam o amor, a igualdade e a violência. Percebe-se que as abordagens propostas condizem com alguns ideais cristãos, mostrando a influência da religião na vida dos educadores. A fala deles se aproxima dos princípios religiosos da caridade e do acolhimento, porém não visa uma aceitação integral da pessoa (com sua sexualidade singular) e sim de uma possível mudança desse desejo. Patrícia, 49 anos, professora de História, afirma: "O respeito pelo outro. Aceitação, mas é quase a mesma coisa, né? O nível de conscientização, os valores... É uma junção de tudo isso.” (Quando perguntados quais as abordagens deviam ser utilizadas numa possível formação).

Quando questionados/as sobre quais profissionais deveriam ministrar esse tipo formação, as opiniões variaram entre competências de psicólogos, sexólogos, professores e médicos. Os argumentos presentes no arranjo de posturas críticas nos indicam que para isso basta que o profissional tenha conhecimento, vivências e relação com as temáticas. Acreditamos que a referência a profissionais da saúde esteja ligada a noção de algo da patologização das condutas, cuja mudança de conduta/estado se daria através da medicalização, terapia ou pedagogias ortopédicas, e detrimento ao debate sobre como essas relações são constituídas no campo da 


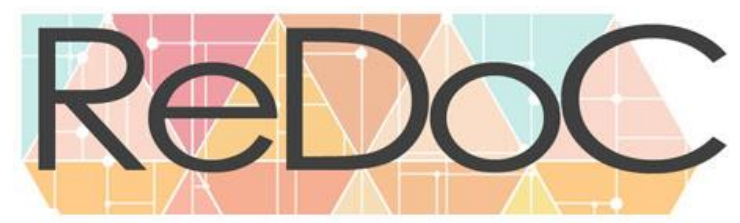

Revista Docência e Cibercultura

cultura e da política. Andrezza, 54 anos, Ensino Fundamental: Ciências e Ensino Médio: Biologia sustenta: “Aquele educador sexual mesmo, né? Da sexologia e que venha com essas, é, essas, como é que vou dizer pra você? Mostrando o comportamento, como é que gente deve se comportar diante desses...".

\section{CONSIDERAÇÕES FINAIS}

Este estudo não teve por objetivo avaliar educadores e educadoras e, tampouco, submeter a escola ao crivo da responsabilização individual pelos discursos heteronormativos que circundam seu cotidiano e os efeitos desses discursos em seu projeto político-pedagógico. Buscamos encontrar neste espaço que nos acolheu (e isto nos oferece um elemento para pensar sobre a disposição de uma instituição como essa em tratar de temas ditos ofensivos aos seus instituídos) e junto a estas e estes interlocutoras/res elementos de problematização sobre os discursos heteronormativos e quais seriam as repercussões destes no cotidiano escolar. Seus argumentos se constituem aqui como pontos de apoio, informando não um problema individual, mas como as práticas pedagógicas são interpeladas por discursos normativos e ao mesmo tempo o quanto podem expressar de resistência e contestação no interior da dinâmica heteronormativa. É preciso descriminalizar educadoras e educadores e pensar que os sujeitos são movimentados em discursos e que estes habitam corpos, produzidos em instituições.

Isso não significa declinar da responsabilização. Certamente precisamos nos responsabilizar por nossas condutas, mas não sem antes compreendermos as condições de possibilidade para a emergência dos problemas de nosso tempo. Acreditamos que somente em interlocução e em tom menos acusativo podemos compreender-intervir diante de uma determinada forma histórica e institucional que assujeita pessoas e os grupos aos grilhões da normalidade.

Enquanto equipe de pesquisa, não nos eximimos de posicionamentos e de conjecturas sobre os conjuntos de enunciados que cercam este cotidiano escolar que assume desde seu compromisso político-institucional um lugar nesta produção. Nosso campo puxou fios de enunciados que forjam uma trama discursiva que, em uma escola confessional e filantrópica, materializam-se na produção dos significados para as noções de humano e para o que se compreende por educação e democracia. 


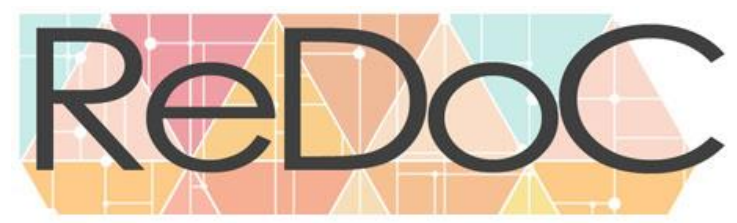

Por outro lado, se não negligenciamos os efeitos dos discursos religiosos, também não tomamos estes como discursos que operam como totalmente excludentes de experiência crítica. Neste aspecto, assumindo que o poder somente se exerce sobre pessoas livres e que nós buscamos interlocuções em um lugar marcado por significações sobre as quais já estávamos cientes de que se tratavam de um lugar de posições normativas sacramentadas, nossa atitude foi a de localizar os enunciados e pontuar seus possíveis efeitos e compromissos normativos.

Nossa contribuição se estabelece na posição de diálogo-crítico, considerando-se que a instituição que nos recebeu conhecia nosso perfil político de pesquisa. Nosso trabalho não é/ não foi aquele de moldar a vontade política dos outros/ das outras, mas de construir com estes/as interlocutoras/res um plano de investigação sobre os movimentos ontológicos que definem o humano possível da educação e assim pensarmos o que estamos tentando fazer de nós mesmos e do que estamos tentando fazer dos outros (Foucault, 2001c/ 1984).

Ponderamos sobre a imprescindível instrumentalização pedagógica das comunidades escolares no manejo das relações sociais que são feitas/tecidas em gênero e sexualidade. O constante movimento de abertura às problematizações sobre o fazer educativo e diagnóstico sobre a produção heteronormativa e das desigualdades sociais (que se exibem tristemente no palco da educação) nos parecem assim caminhos possíveis construir relações sociais menos arbitrárias, bem como enfrentar os efeitos violentos dessas arbitrariedades, como a violência de gênero, formas de abuso e objetificação da sexualidade, discriminação, preconceito e a patologização, tutela e/ou tentativa de correção/'ortopedia' das diferenças.

\section{REFERÊNCIAS}

BENTO, B. (2011). Na Escola se aprende que a diferença faz a diferença. Revista de Estudos Feministas, Florianópolis, 19(2): 336, p. 549-559.

BORGES, Z. N.; e Meyer, D. E. (2008). Limites e possibilidades de uma ação educativa na redução da vulnerabilidade à violência e à homofobia. Ensaio: Aval. Pol. Públicas. Educ., Rio de Janeiro, v.16, n. 58, p.59-76.

BORRILO, D. (2000). L'homophobie. Paris : Presses Universitaires de France. 


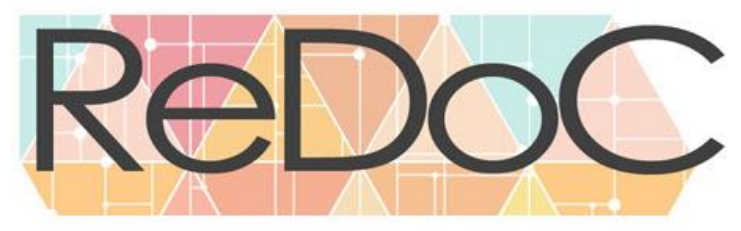

Revista Docência e Cibercultura

BRITZMAN, D. (1996). O que é essa coisa chamada amor. Identidade homossexual, educação e currículo. Educação e Realidade, v. 21(1), 71-96.

DORNELLES, P.G. A (hetero)normalização dos corpos em práticas pedagógicas da Educação Física escolar. Tese (Doutorado em Educação) - Universidade Federal do Rio Grande do Sul, Faculdade de Educação, Programa de Pós-Graduação em Educação, Porto Alegre, 2013.

DORNELLES, P.G. ; MEYER, D. E. E. (2013). Corpo, gênero e sexualidade na escola: cenas contemporâneas, políticas emergentes e teorias potenciais. In Dornelles, P. G.; Givigi, A. C. (Org.). O recôncavo baiano sai do armário: universidade, gênero e sexualidade. $1^{\text {a }} \mathrm{ed}$.Cruz das Almas: Editora UFRB, p. 31-54.

FOUCAULT, M. (2004). A arqueologia do saber. [1969]. Rio de Janeiro: Forense Universitária.

FOUCAULT, M. (2001a). L'éthique du souci de soi comme pratique de la liberté. [1984]. In Foucault, M. Dits et écrits II, 1976-1988. Paris: Gallimard.

FOUCAULT, M. (2001b). Foucault.[1984]. In M. Foucault, Dits et écrits II, 1976-1988, Paris, Éditions Gallimard.

FOUCAULT, M. (2001c). Le souci de la vérité. [1984]. In M. Foucault, Dits et écrits II, 19761988. Paris: Gallimard.

FOUCAULT, M. (1995). Sobre a genealogia da ética: uma revisão do trabalho. In H. Dreyfus, e P. Rabinow, Michel Foucault: uma trajetória filosófica, Rio de Janeiro: Forense Universitária.

FOUCAULT, M. (1997). História da sexualidade. A vontade de saber. [1976]. Rio de Janeiro: Graal.

Junqueira, R. D. (2009). Homofobia nas Escolas: um problema de todos. In

JUNQUEIRA, R. D. (Ed.). Diversidade Sexual na Educação: problematizações sobre a homofobia nas escolas. Brasília: Ministério da Educação, Secretaria de Educação Continuada, Alfabetização e Diversidade.

LOURO, G. L. (2010). Pedagogias da sexualidade. In Louro, G. L. (Ed.). O corpo educado: Pedagogias da sexualidade. Belo Horizonte: Autêntica.

LOURO, G. L. (2000). Currículo, gênero e sexualidade. Porto: Porto Editora.

LOURO, G. L. (2012). Gênero, sexualidade e educação: Uma perspectiva pós- estruturalista. Petrópolis: Vozes. 


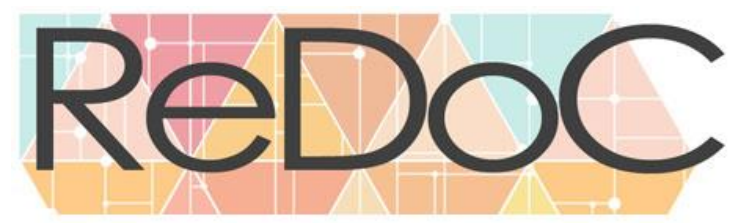

LOURO, G. L. (2009). Heteronormatividade e Homofobia. In R. D. Junqueira (Ed.), Diversidade Sexual na Educação: problematizações sobre a homofobia nas Escolas. Brasília: Ministério da Educação, Secretaria de Educação Continuada, Alfabetização e Diversidade.

Meyer, D. E. (2003a). Educação, saúde e modos de inscrever uma forma de maternidade nos corpos femininos. Revista Movimento. Porto Alegre, v.9, (3), 33-58.

Meyer, D. E. (2003b). Gênero e educação: teoria e política. In G. L. Louro; J. Felipe; S.V. Goellner (Eds.). Corpo, Gênero e Sexualidade: Um debate contemporâneo na educação. Petrópolis: Vozes.

NATIVIDADE, M. (2009). Sexualidades ameaçadoras: religião e homofobia(s) em discursos evangélicos conservadores. Sexualidad, Salud y Sociedad - Revista Latinoamericana, (2), 121161.

QUARTIERO, E. T; Nardi, H. C. (2012) Educando para a diversidade: desafiando a moral sexual e construindo estratégias de combate à discriminação no cotidiano escolar. Sexualidad, Salud y Sociedad, Rio de Janeiro, v. 11, p. 59-87.

SEFFNER, F. (2011). Avaliação dos Programas Federais de Respeito à Diversidade Sexual nas Escolas. Audiência Pública. Procuradoria Geral da República/ PGF, Brasília. Disponível em: http://pfdc.pgr.mpf.mp.br/informacao- e-comunicacao/eventos/direitos-sexuais-ereprodutivos/audiencia-publica- avaliacao-programas-federais-respeito-diversidade-sexual-nasescolas/apresentacoes/fernando-seffner-ufrgs

SILVA, Tomaz Tadeu. (2000). Teoria cultural e educação: um vocabulário crítico. Belo Horizonte: Autêntica.

SILVA, Tomaz Tadeu. (2007). A produção social da identidade e da diferença. In T. T. Silva (Ed.). Identidade e diferença. A perspectiva dos estudos culturais. Rio de Janeiro: Vozes. 